\title{
A novel in-service nursing education optimizing theory of technological competency as caring in nursing
}

\author{
Youko Nakano ${ }^{1}$, Tetsuya Tanioka*2, Rozzano Locsin ${ }^{2}$, Misao Miyagawa $^{3}$, Tomoya Yokotani ${ }^{4}$, Yuko Yasuhara ${ }^{2}$, \\ Hirokazu Ito $^{2}$, Elmer Catangui ${ }^{5}$ \\ ${ }^{1}$ Kagawa University Hospital, Kagawa, Japan \\ ${ }^{2}$ Department of Nursing, Institute of Biomedical Sciences Tokushima University, Graduate School, Tokushima, Japan \\ ${ }^{3}$ Department of Nursing, Faculty of Health and Welfare, Tokushima Bunri University, Tokushima, Japan \\ ${ }^{4}$ Tokushima University Hospital, Tokushima, Japan \\ ${ }^{5}$ Graduate School, St. Paul University Philippines, Tuguegarao, Philippines
}

Received: May 21, 2019

DOI: $10.5430 /$ jnep.v9n11p85
Accepted: August 13, 2019

Online Published: August 29, 2019

URL: https://doi.org/10.5430/jnep.v9n11p85

\begin{abstract}
Contemporary and future nursing practices are increasingly being designed with nursing theories as to its foundation. The aim of this article is to describe an in-service education program for nursing administrators centered on the theory of Technological Competency as Caring in Nursing (TCCN). This theory is framed chiefly within the concepts of technology, caring, nursing, and technological competency. Influencing the significance of in-service education is theory-based practice with advancing technologies in human caring. The in-service education program was organized as a five-month, one-hour a month lecture and discussion series. In each session, educational contents are focused on the nursing process as caring based on the theory of TCCN. This education is a plan that will gradually educate the nurse manager group, the mid-level nursing staff group, and finally to the staff nurse group. This hierarchically organized in-service educational plan aims to systematically improve their knowledge and practice situation for three years. During each session, theory content included "knowing persons as caring" as the nursing process based on the theory of TCCN. Participating in these lectures are envisioned to increase knowledge about TCCN for the purpose of improving the overall quality of nursing care outcomes. An organized educational plan will improve the quality of nursing care as influenced by the use of the theory of TCCN in the practice of nursing.
\end{abstract}

Key Words: In-service education, Technological Competency as Caring in Nursing, Theory-based nursing practice, Nursing care

\section{INTRODUCTION}

Theory-based nursing practice is a requisite for quality nursing and health care. ${ }^{[1]}$ The value of human caring, particularly in hospital settings, has been steadily increasing. ${ }^{[2]}$ Using advanced medical technologies, the growing number of older patients, the severity of patient conditions, and the shortening of the average length of patient hospital stay al- together affect the quality of hospital health care services. ${ }^{[3]}$ Similarly, the quality of nursing care has also greatly affected the safety, ${ }^{[1-5]}$ and satisfaction of patients ${ }^{[6,7]}$ which in turn, affect the overall outcomes of healthcare ${ }^{[8]}$ Often addressed as a consequence of mediocre practice is the insufficient time made possible to know patients. Time for patient care has become increasingly limited and patients' hospital stays

\footnotetext{
*Correspondence: Tetsuya Tanioka; Email: tanioka.tetsuya@tokushima-u.ac.jp; Address: Department of Nursing Outcome Management, Institute of Biomedical Sciences, Tokushima University, Graduate School, 18-15 Kuramoto-cho 3, Tokushima, 770-8509, Japan.
} 
been considerably shortened. Furthermore, environmental changes have affected the overall health care quality provided by hospital staff.

Caring as a central concept of nursing has led to the development of several caring theories ${ }^{[9]}$ influential to human health and well-being. Well-known theories of caring include Madeleine Leininger's Theory of Transcultural Caring, and Jean Watson's Theory of Transpersonal Human Caring. Both were formulated in the 1970s. ${ }^{[9]}$ However, today, caring in nursing has become the quintessential element and basis of quality nursing care. ${ }^{[10]}$ Dominating this contemporary view is Locsin's Technological Competency as Caring in Nursing (TCCN), in which the purpose of being technologically competent is to know persons more fully as caring. ${ }^{[10]}$ Healthcare has greatly changed due to issues such as disease structure changes and a rapidly aging population with decreasing birthrates. Healthcare and care providing systems are evolving. Accordingly, the nursing profession with advanced practical competence to cope with diversification and complication of medical needs are imperative. ${ }^{[1]}$ Also, today's innovative technologies have changed many ways of practicing health care particularly in hospital settings. ${ }^{[12]}$ With technological developments such as the Internet of Things (IoT) (refers to the networking capability connecting diversified objects using the intranet, internet, and Artificial Intelligence, information technologies have overwhelmed health care practice). ${ }^{[13]}$ The development of the personal computer, the intranet and the internet are transforming the work methods of nurses, physicians, and other healthcare staff in hospital settings.

Relationships between nursing, caring, and technology are well delineated and explicated in the middle range theory of TCCN. ${ }^{[14]}$ It provides the necessary elements to guide the relevant and valuable practice processes of nursing. ${ }^{[15]}$ The TCCN serves as a cornerstone to the practice of nursing as knowing persons as caring. This is Locsin's theory ${ }^{[15]}$ in which technological competency is understood and practiced as expressing caring. In the highly advanced health care area, it is affirmed that the technological competency of nurses in their practice of nursing is critically important for expressing human health care. ${ }^{[16]}$

Locsin $^{[15]}$ has declared that "in nursing, it is important to fully understand the persons, who are unpredictable and constantly changing", and "by using technologies of care, it is possible to know and understand the patients more fully as persons". ${ }^{[17]}$ However, if practicing nursing without the theoretical base of the TCCN that the nurse is simply being technically adept, it might only professionally have engaged in a practice that is uniquely professional nursing.
For these reasons, nurse managers are identified as the responsible group for enhancing patient care services towards enhancing collaborative research ${ }^{[18]}$ and practice. In this situation, leadership-skill is important ${ }^{[19]}$ and essential as elements to improve patient experiences, and the quality of their nursing care. Clinically competent nurses engage in collaborative working relationships, autonomous nursing practice, adequate staffing, optimizing competent nursing practice, managerial support and patient-centered culture ${ }^{[20]}$ altogether creating a mil theieu of human health care that assures quality human care.

However, education about caring in nursing in Japan was only known a short time ago and is not often found essential in basic nursing education. Some nurses have not received educational content on caring in nursing. Therefore, the development of in-service training incorporating the theory of TCCN is important.

The in-service education programs for nursing staff have been implemented in various forms and methods. ${ }^{[21]}$ Unfortunately, there are few known reports on its impact, particularly on its occupational outcomes.

To improve educational outputs, it is crucial to understand, develop, and adopt new models of in-service education programs, particularly for practicing nurses.

A patient suffering from their disease and the effects of treatments are valuable information for enhancing quality nursing care. ${ }^{[22]}$ Nursing practitioners have to share their experiences with nursing situations as essential to appreciating and knowing patients' conditions. ${ }^{[23]}$ To realize the impact of nursing from a point of view of TCCN, it is necessary to design, develop and evaluate an in-service educational program utilizing a theory-based practice.

Curriculum, in-service training, continuing education, and other educational efforts can target these concepts as a way of augmenting knowledge, skills, and abilities in care coordination and clinical leadership in nursing. ${ }^{[18]}$ The development of a novel in-service education program for nurses was planned based on the critical need for theory-based practice. To address this paucity of knowledge about its practice, an in-service education program is highly recommended based on the concepts and assumptions of the TCCN. It is presented here that through TCCN, the practice of nursing is 'knowing persons as caring'- a process through which it is realized.

The universal technological domain (UTD) ${ }^{[24]}$ is a technological encounter that occurs in the environment. The UTD is the all-encompassing unity of 'space and technology' in which the dynamic engagement of the process of nursing is known. This domain is where all technological skills 
and techniques of engagement occur between technologies and human persons, wherein explications and utilization of knowing persons as caring is illuminated as the technological encounter.

Within the UTD, sophisticated technologies are accepted as integral and essential to contemporary life. ${ }^{[2]}$ That is coextensive with humans and their environment. In human healthcare, the risk for depersonalizing persons receiving care renders the preservation of humanness as essential, particularly in technology-dense arenas. Nurses are challenged to sustain their caring nursing practice while responding to the complex technological demands of modern healthcare. ${ }^{[25]}$

Three key elements demonstrate the fundamental process of 'knowing persons as caring' within the UTD, grounded in the TCCN theory: technological knowing, mutual designing, and participative engaging. Underpinning this process of nursing are concepts of human naturalness, human wholeness, and nursing technology connoisseurship. ${ }^{[25]}$ From the perspective of the TCCN, the nurse appreciates and knows persons more fully as caring persons, who are active participants in their care rather than as passive recipients of their care. Doing so advances the preservation of humanness as assumed in the theory.

The TCCN is the theoretical framing of a practice process exhibiting its movement as dynamic, while instantaneously showing a continuous course for understanding people as always whole. ${ }^{[26]}$ The expectation of the process of knowing persons- as-caring in nursing is to enhance mutual trust and respect between the nurse and patient in order for nursing to occur. ${ }^{[27]}$

The use of technologies in nursing has expanded, is constantly changing, and continuing to respond to the demands of quality nursing care. Meanwhile, care in nursing as an essential form of knowledge, forms the basis for understanding persons, driving the practice of integrating technical capabilities in nursing as expressing caring.

The aim of this article is to describe an in-service education program for nursing administrators centered on the theory of TCCN.

\section{METHOD}

\subsection{Description of a proposed in-service education pro- gram based on the theory of TCCN}

Through the TCCN, the practice of nursing is lived as knowing persons as caring as guide for nursing practice. The expected results are human caring and human health and well-being based on the premise of the TCCN theory. The proposed in-service education program is organized as a lecture session of 1-hour every month over a five-month period. To increase nurses' knowledge of the theory of TCCN, expected outcomes of the proposed in-service education program are: (1) to increase knowledge on the theory of TCCN, (2) to foster understanding of patients by nursing management based on patient-centered care, and (3) to improve quality of nursing services grounded in the theory.

In each session, educational contents are focused on understanding the nursing process underpinning "knowing persons as caring" based on the theory of TCCN. Participating in these lectures will provide increased knowledge of the theory of TCCN to improve the quality of nursing care. This education program is planned to gradually educate the nurse manager group, followed by the mid-level nursing staff group, and finally the staff nurse group. As a result, this hierarchically organized in-service educational plan is aimed at systematically improving their knowledge and practice acumen towards quality nursing care within a three-year period about theoretically-based nursing practice.

During the first year of the program, in-service education is focused specifically on nurse managers on the theoretical basis of nursing from the theory of TCCN. In order to improve the quality of nursing care practice, the managers are expected to become role models for the practice of nursing that is based on the theory of TCCN. It is also envisioned that the nurse managers will act as experts in the practice of nursing using the "knowing persons as caring" process of nursing based on the theory of TCCN. Subsequently, in the second year, this educational program will focus on the midlevel nursing staff members. In the third year, this in-service program will be focused on staff nurses. As a result, this hierarchically organized educational plan aimed at systematically improving the competent use of technologies of care as expressions of caring in nursing is expected to improve quality nursing care.

\subsection{Content of lectures based on the theory of TCCN}

Table 1 shows the content of the in-service education program by Dr. Rozzano Locsin and Dr. Tetsuya Tanioka. In each session, theory contents have focused on the assumptions, concepts, nursing process and practice elements demonstrated as expressions of caring grounded in the theory of TCCN. The contents of each chapter as described below are derived from the specific chapters of the 2005 book and translated into the Japanese language in 2009 by Tanioka et al. ${ }^{[27]}$ The goodness of this in-service program is that Dr. Locsin, a nursing theorist of the TCCN is giving lectures directly. Therefore, it is possible to inform participants about the correct way of thinking (see Figure 1). 
Table 1. Syllabus on TCCN, ${ }^{[27]}$ by Rozzano Locsin and Tetsuya Tanioka Lecture/Presentation

\begin{tabular}{|c|c|c|c|c|}
\hline Month & Topic & $\begin{array}{l}\text { Chapter of } \\
\text { the book }\end{array}$ & Questions & Responses \\
\hline 1 & $\begin{array}{l}\text { Introduction to the } \\
\text { Theory of TCCN }\end{array}$ & 1 & $\begin{array}{l}\text { 1) What is Caring and Nursing? } \\
\text { 2) What is technological } \\
\text { competency as caring? } \\
\text { 3) Why do we need TCCN theory? }\end{array}$ & $\begin{array}{l}\text { 1) Caring is: } \\
\text { Nursing is: } \\
\text { 2) TCCN is } \\
\text { 3) We need the theory of TCCN because: }\end{array}$ \\
\hline 2 & $\begin{array}{l}\text { Understanding } \\
\text { Technological } \\
\text { Competency through } \\
\text { philosophy and } \\
\text { nursing }\end{array}$ & 2 & $\begin{array}{l}\text { 1) What is technology? } \\
\text { 2) What is technology and } \\
\text { nursing? } \\
\text { 3) Description of Nursing Practice }\end{array}$ & $\begin{array}{l}\text { 1) Technology is: } \\
\text { 2) Technology and nursing is: } \\
\text { 3) Nursing practice focus on: service } \\
\text { improvement and innovations }\end{array}$ \\
\hline 3 & $\begin{array}{l}\text { Technological } \\
\text { Competency as an } \\
\text { Expression of Caring } \\
\text { in Nursing }\end{array}$ & 5 & $\begin{array}{l}\text { 1) What is Technique, and what is } \\
\text { technology? } \\
\text { 2) What are the expressions of } \\
\text { caring? }\end{array}$ & $\begin{array}{l}\text { 1) The difference between technique and } \\
\text { technology are: } \\
\text { 2) Expressions of caring is: }\end{array}$ \\
\hline 4 & $\begin{array}{l}\text { A model for practice: } \\
\text { Technological } \\
\text { Competency as Caring }\end{array}$ & 7 & $\begin{array}{l}\text { 1) Assumptions of theory } \\
\text { 2) What are descriptions of } \\
\text { wholeness of persons as a concept }\end{array}$ & $\begin{array}{l}\text { 1) List the assumptions of the theory } \\
\text { 2) List the many description of } \\
\text { wholeness } \\
\text { 3) Describe the similarities and } \\
\text { differences of: } \\
\text { Wholeness of persons; whole persons }\end{array}$ \\
\hline 5 & $\begin{array}{l}\text { Knowing persons as } \\
\text { caring in Nursing }\end{array}$ & 8 & $\begin{array}{l}\text { 1) What are the processes of } \\
\text { nursing based on the theory of } \\
\text { technological competence in } \\
\text { nursing? } \\
\text { 2) What are the ways of knowing } \\
\text { in nursing? }\end{array}$ & $\begin{array}{l}\text { 1) Processes of nursing based on the } \\
\text { theory of technological competence in } \\
\text { nursing } \\
\text { 2) Ways of knowing in nursing }\end{array}$ \\
\hline
\end{tabular}

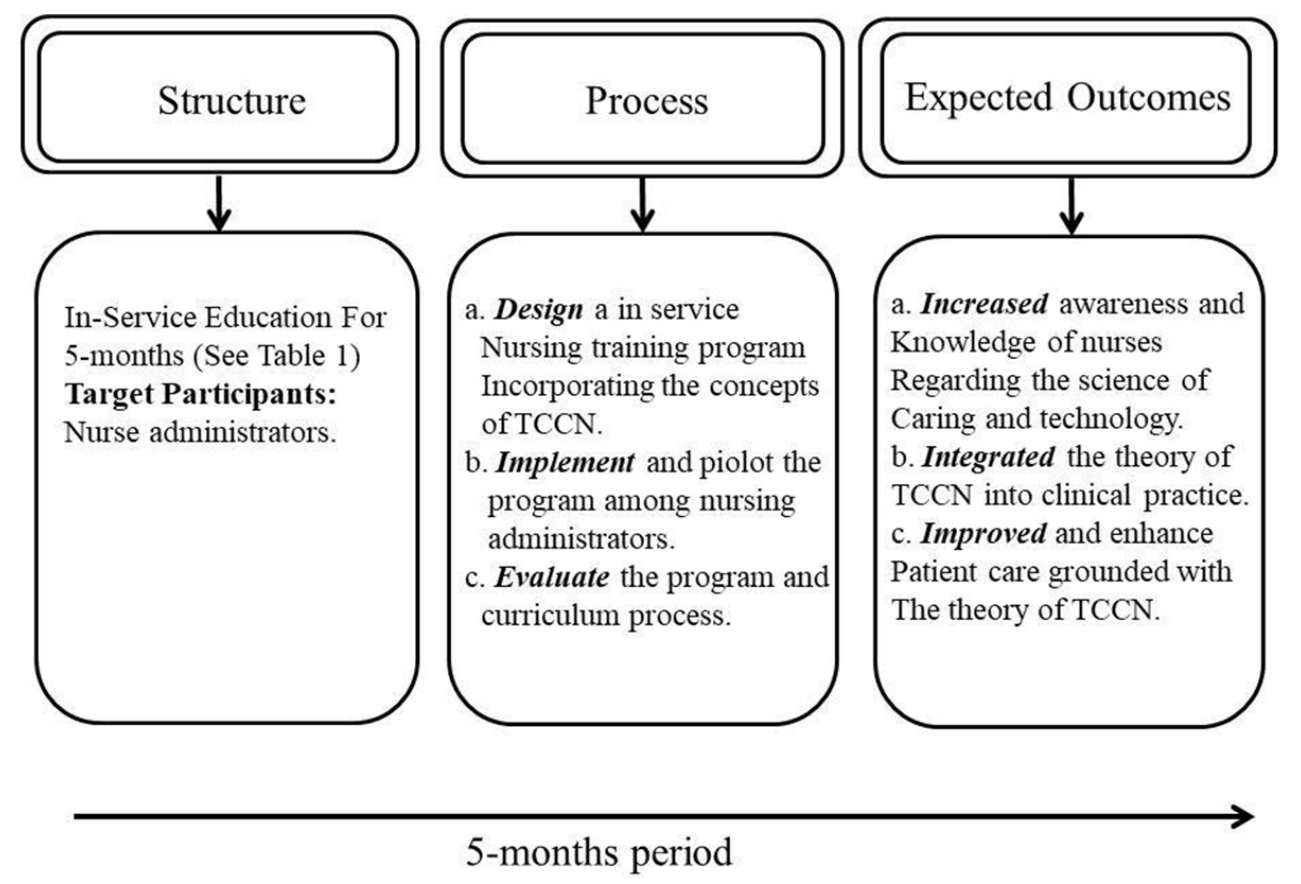

Figure 1. In-service Nursing Education Program Optimizing Theory of TCCN 
Since the participants are Japanese nurses, Dr. Tanioka supports Dr. Locsin's speech as a translator. In order to replicate this teaching method, it is important for the educator to understand the TCCN theory correctly and correctly teach it to the participants in the in-service education.

\section{Chapter 1, Introduction to the Theory of TCCN}

This topic introduces the theory focusing on the definition and description of key concepts such as caring in nursing, technologies in health care, technological competency as caring, and the value of expressing caring in nursing.

Chapter 2, Understanding Technological Competency through Philosophy and Nursing

The topic facilitates the discussion on knowing persons as caring, explaining multiple ways of knowing in nursing, and enhancing the focus of nursing practice as using technologies in order to know persons as caring.

Chapter 5, Technological Competency as an Expression of Caring in Nursing

Technological Competency is explained as a way to understand nursing practice as knowing persons through various technologies in health care. Being technologically competent is being caring.

Chapter 7, A model for practice: Technological Competency as Caring

How do we know that technological competency is caring? Optimized in Simone Roach's Attributes of Caring is the statement, "competency without compassion is brutal, and compassion without competence is being irresponsible". Roach's Caring attributes and Mayeroff's ingredients of caring provide structure to being a caring person.

\section{Chapter 8, Knowing Persons as Caring in Nursing}

How is knowing persons as caring practiced through technological competency as an expression of caring in nursing? Technological knowing, mutual designing, and participative engaging altogether promote the practice in which persons are understood as participants in their care, rather than simply objects of our care.

\section{RESULT AND DISCUSSION}

\subsection{Significance of the proposed in-service education program}

The ultimate goal of the in-service education program is to enhance the understanding of the theory of TCCN as a future basis for expanding the caring practice of nursing in acute care settings. Guided by 'knowing persons as caring' as the process of nursing, the nurse managers who promote a caring practice environment for the department of nursing was realized. Quality patient care through nursing care is aimed to achieve or improve quality nursing care outcomes for patients in acute care settings.

With the theory of Nursing As Caring ${ }^{[28]}$ supporting the view that nurse administrators' believing that nurses require new ways of being with the person, expressions of caring in nursing can be realized. The nursing administrators are expected to model ways of being with others, portraying respect for persons as caring: through modeling, others grow in their competency to know others as persons and in doing so, express their caring as nursing. Creating and sustaining environments that nurture and value the practice and study of nursing remain the challenge facing nurses and nurse administrators, particularly those who are caught in the maze of various organizational bureaucratic structures. Systems, especially in health care institutions are often dominated by measurable outcomes understood as the only evidence for success. This view perpetuates existing ways of being among nursing leaders, even though their staff members may repeatedly question the legitimacy of actions flowing from these structures.

\subsection{Ways of evaluating educational effects based on the- ory of TCCN}

How can the practice of 'knowing persons as caring' based on the theory of TCCN, remain relevant in today's health care practice systems? How can nursing be expressed as caring through outcomes of practice that is seemingly based on the TCCN?

In 2011, the Technological Competency as Caring in Nursing Instrument (TCCNI) was developed (Locsin, 2011) ${ }^{[29]}$ to determine "technological competency as expression of caring in nursing" among practicing nurses. The instrument was based on the initial version of the Technological Caring Instrument (TCI $)^{[30]}$ developed in 1999 that measured technological caring of nurses. While the TCCNI was translated into other languages, no instrument measuring TCCN among Japanese nurses has been available. In 2009, from the original TCCNI, the Japanese version was translated by Tetsuya Tanioka. ${ }^{[31]}$ The reverse translation using a professional English-to Japanese-to-English translator confirmed the accuracy of the translations.

To measure the expected effect of the in-service education program, it is suggested to design and develop a measurement scale. Measuring the practical situations of nursing in in-service programs is essential for determining the effect of the educational program. Locsin and Tanioka's team have been developing the Technological Competency as Caring in Nursing Instrument-R (Revised version TCCNI-R). This TCCNI-R will focus on evaluating the degree of knowledge 
improvement about the TCCN before and after the five educational sessions in order to illuminate the theory content and its use.

Evidences of evaluating the practice value of the theory of TCCN in previous international research studies are focused on exploring the experiences of nurses who are caring for patients and their families, and experiences of patients being cared for with technologies. ${ }^{[32]}$ Other studies are concerned about the caring behaviors of nurses using evaluative scales. ${ }^{[33]}$ In practice, active educational programs for nursing staff have been implemented in other ways, however, there are no publications found on the 'effects' or outcomes from these studies, but instead, only narrative reports of how the programs are conducted, such as using active drills for nursing care. ${ }^{[34,35]}$

\subsection{Limitation}

A novel in-service Nursing Education Plan and its evaluation in this service are not actually evaluated and need to be evaluated in future practice.

\section{Conclusion}

Nursing practice is expressed as a demonstration of the skills of nursing care. Such practice also includes an exhibition of human caring theoretically grounded in a framework of nursing. One such theory is the theory of TCCN. The acquisition of technological competencies is for the purpose of demonstrating technological knowing which leads to outcomes of knowing persons more fully as caring persons. There is a possibility that in-service educational programs based on the theory of TCCN can provide outcomes toward promoting enhanced patient understanding, thereby fostering quality nursing care management focused on patient-centered care, thereby improving quality nursing care services.

\section{ACKNOWLEDGEMENTS}

This work was supported by JSPS KAKENHI, Grant-in-Aid for Scientific Research (C) Grant Number JP17K12159.

\section{CONFlicts OF InTEREST Disclosure}

The authors declare that there is no conflict of interest.

\section{REFERENCES}

[1] Mitchell PH. Defining Patient Safety and Quality Care. In: Hughes RG, editor. Patient Safety and Quality: An Evidence-Based Handbook for Nurses. Rockville (MD): Agency for Healthcare Research and Quality (US); 2008 Apr. Chapter 1. Available from: https: //www.ncbi.nlm.nih.gov/books/NBK2681/

[2] Wunderlich GS, Sloan F, Davis CK. Nursing Staff in Hospitals and Nursing Homes: Is It Adequate?.Washington, DC: National Academies Press US; 1996.

[3] Aiken LH, et al. Patient safety, satisfaction, and quality of hospital care: cross sectional surveys of nurses and patients in 12 countries in Europe and the United States. BMJ. 2012; 344. PMid:22434089 https://doi.org/10.1136/bmj.e1717

[4] Deborah KG, Blegen MA. Competence and Certification of Registered Nurses and Safety of Patients in Intensive Care Units. American Journal of Critical Care. 2009 Mar; 18 (2): 106-114. PMid:19255100 https://doi.org/10.4037/ajcc2009487

[5] Ballard K. Patient Safety: A Shared Responsibility. Online Journal of Issues in Nursing. $2003 \mathrm{Feb}$; 8(3): Manuscript 4.

[6] Dingman SK, et al. Implementing a Caring Model to Improve Patient Satisfaction. The Journal of Nursing Administration. 1999 Dec; 29(12): 30-7. https://doi.org/10.1097/00005110-1999120 00-00007

[7] Radtke K, Improving patient satisfaction with nursing communication using bedside shift report. Clin Nurse Spec. 2013; 27(1): 19-25. PMid:23222024 https://doi.org/10.1097/NUR.0b013e3182 777011

[8] Mallidou AA, Cummings GG, Estabrooks CA, et al. Nurse specialty subcultures and patient outcomes in acute care hospitals: A multiple-group structural equation modeling. Int J Nurs Stud. 2011; 48(1): 81-93. PMid:20598308 https://doi.org/10.1016/j.ij nurstu.2010.06.002
[9] McCance TV, McKenna HP, Boore JR. Caring: theoretical perspectives of relevance to nursing. J Adv Nurs. 1999; 30(6): 1388-95. PMid:10583650 https://doi.org/10.1046/j.1365-2648.19 99.01214. $\mathrm{x}$

[10] Boykin A, Schoenhofer S. Nursing as caring, A model for transforming practice. Boston, MA: Jones and Bartlett; 2001; 1-10.

[11] Fukada M. Nursing Competency: Definition, Structure and Development. Yonago Acta Med. 2018; 61(1): 1-7. https://doi .org/10 .33160/yam. 2018.03.001

[12] Thimbleby H. Technology and the Future of Healthcare. Journal of Public Health Research. 2013; 2(3): e28. PMid:25170499 http://doi.org/10.4081/jphr.2013.e28

[13] Dimitrov DV. Medical Internet of Things and Big Data in Healthcare. Healthcare Informatics Research. 2016; 22(3): 156163. PMid:27525156 http://doi.org/10.4258/hir.2016. 22 . 3.156

[14] Locsin R. Technological Competency as Caring in Nursing: CoCreating Moments in Nursing Occurring Within the Universal Technological Domain. The Journal of Theory Construction and Testing. 2016; 20: 5-11.

[15] Locsin R. Technological Competency as Caring in Nursing: A Model for Practice. Sigma Theta Tau International Press; Indianapolis, Indiana. 2005

[16] Locsin RC, Purnell M. Advancing the Theory of Technological Competency as Caring in Nursing: The Universal Technological Domain. International Journal for Human Caring. 2015; 19(2): 50-54. https://doi .org/10.20467/1091-5710.19.2.50

[17] Locsin R. Technological Competency as Caring in Nursing: A Model for Practice (rev ed). Silliman University Press; Dumaguete City, Philippines. 2016.

[18] Joseph ML, Huber DL. Clinical leadership development and education for nurses: prospects and opportunities. J Healthc Leadersh. 
2015; 7: 55-64. PMid:29355179 https://doi.org/10.2147/JH L. $\mathrm{S} 68071$

[19] Nursing Times. Leadership-Skills-for-Nurses. Available from: https://www.nursingtimes . net/Journals/2011/08/24/j /n/i/Leadership-Skills-for-Nurses.pdf

[20] Kieft RAMM, de Brouwer BBJM, Francke AL, et al. How nurses and their work environment affect patient experiences of the quality of care: a qualitative study. BMC Health Services Research. 2014; 14: 249. PMid:24923663 https://doi .org/10.1186/1472-696 3-14-249

[21] Chaghari M, Saffari M, Eeadi A, et al. Empowering Education: A New Model for In-service Training of Nursing Staff. Journal of Advances in Medical Education \& Professionalism. 2017; 5(1): 26-32.

[22] Jones T. Outcome Measurement in Nursing: Imperatives, Ideals, History, and Challenges. OJIN: The Online Journal of Issues in Nursing. 2016; 21(2): Manuscript 1.

[23] Bramley L, Matiti M. How does it really feel to be in my shoes? Patients' experiences of compassion within nursing care and their perceptions of developing compassionate nurses. Journal of Clinical Nursing. 2014; 23(19-20): 2790-9. PMid:24479676 https: //doi.org/10.1111/jocn. 12537

[24] Locsin RC. The Co-Existence of Technology and Caring in the Theory of Technological Competency as Caring in Nursing. J Med Invest. 2017; 64(1.2): 160-164. PMid:28373615 https://doi.org/10.2 $152 / j \mathrm{mi} .64 .160$

[25] Locsin R, Purnell M. Advancing the Theory of Technological Competency as Caring in Nursing: The Universal Technological Domain. International Journal for Human Caring. 2015; 19(2): 50-54. https://doi.org/10.20467/1091-5710-19.2.50

[26] Locsin R. Technologic competence as caring in critical care nursing. Holist Nurs Pract. 1998 Jul; 12(4): 50-6. PMid:9849208 https://doi.org/10.1097/00004650-199807000-00008
[27] Locsin R. Rozzano Locsin's Technological Competency as Caring and the Practice of Knowing Persons in Nursing. Nursing Theories Nursing Practice third edition. 2010; 460-471.

[28] Boykin A, Schoenhofer S. Nursing as caring, A model for transforming practice. Boson, MA: Jones and Bartlett. 2001; 32-39.

[29] Parcells D, Locsin R. Development and psychometric testing of the technological competence as caring in nursing instrument. International Journal for Human Caring. 2011; 15(4): 8-13. https : //doi.org/10.20467/1091-5710.15.4.8

[30] Locsin R. Development of an instrument to measure technological caring in nursing. Nursing and Health Sciences. 1999; 1: 27-34. PMid:10894649 https ://doi .org/10.1046/j.1442-2018.19 $99.00005 . \mathrm{x}$

[31] Tanioka T. The Theory of Technological Competency as Caring in Nursing and Its Instruments (TCCNI) Within the Japanese Nursing System: Futurist Developments and Utilization. In: Locsin RC and Warapon Kongswan Ed., The Evolution of the Theory of Technological Competency as Caring in Nursing: A Middle-Range Theory of Nursing, Chanmuang Press; Hatyai. 2018; 145-154.

[32] Biswas SR, Kongsuwan W, Matchim Y. Technological Competency as Caring in Nursing as Perceived by ICU Nurses in Bangladesh and Its Related Factors. Songklanagarind Journal of Nursing. 2016; 36(1).

[33] Edvardsson D, Mahoney AM, Hardy J, et al. Psychometric performance of the English language six-item Caring Behaviours Inventory in an acute care context. Journal of Clinical Nursing. 2015; 24(1718): 2538-2544. PMid:25959520 https://doi .org/10.1111/jo cn. 12849

[34] Fumiko Y. Nursing Education Incorporation caring. JAPANESE JOURNAL OF BEHAVIORAL SCIENCE. 2016; 31(2): 10-13. (In Japanese)

[35] Murata Y, Yoshida K, Shindo Y. Caring provided by nurse managers in staff management Japanese Red Cross Hiroshima Coll. Nurs. 2013; 13: 9-17. (In Japanese) 